\title{
GÖZENEK VE GÖZENEK TIPLERI
}

\author{
Muhsin EREN1* \\ ${ }^{1}$ Mersin Üniversitesi, Mühendislik Fakültesi, Jeoloji Mühendisliği Bölümü 33343 Çiftlikköy/Mersin \\ ORCID No : http://orcid.org/0000-0001-7594-1153
}

\section{Gözenek \\ Gözeneklilik \\ Gözenek tipleri \\ Gözenek kökeni \\ Kayaç dokusu}

Anahtar Kelimeler

\section{Öz}

Bu makale tortul kayacın en önemli özelliklerinden biri olan gözenekleri tanitmakta ve daha iyi anlaşılmasına katkıda bulunmayı amaçlamaktadır. Gözenekler özellikle karbonat kayaçlarında ortamsal ve diyajenetik değişimlerin yorumlanmasında ve rezervuar analizlerinde önemlidir. Gözeneklilik kayacın boşluk hacminin, kayacın toplam hacmine oranı olarak tanımlanır. Gözenekler kökensel açıdan birincil ve ikincil gözeneklilik olmak üzere başlıca iki gruba ayrılır. Birincil gözeneklilik kayaç ilk çökeldiğinde oluşan gözenek türlerini içerir. İkincil gözeneklilik ise diyajenez sırasında çözünme, dolomitleşme, yeniden kristallenme ve çatlak oluşumuna bağlı olarak oluşur. Íkincil gözenekler gömülme derinliğine bağlı olarak öjenetik (sığ gömülme), mezojenetik (derin gömülme) ve telejenetik (gerileyici gömülme) olmak üzere üçe ayrılır. Ayrıca gözenekler geometrik özelliklerine ve kayaç dokusuyla olan ilişkisine göre de üçe ayrılır. Bunlar doku seçimli, doku seçimli olmayan ve doku seçimli veya olmayandır. Boyutlarına göre de gözenekler üç grupta toplanır: mikrogözenek < $4 \mu \mathrm{m}$, orta gözenek $4 \mu \mathrm{m}-4 \mathrm{~mm}$, ve büyük gözenek 4-256 mm.

\section{PORE AND PORE TYPES}

\begin{tabular}{l}
\hline Keywords \\
\hline Pore \\
Porosity \\
Pore types \\
Pore origin \\
Rock fabric
\end{tabular}

Abstract

This paper introduces pores, one of the most important features of sedimentary rock, and aims to contribute to its better understanding. Pores are especially important in the interpretation of environmental and diagenetic changes in the carbonate rocks and in the reservoir analysis. Porosity is defined as the ratio of the pore volume of the rock to the total volume of the rock. The pores are originally divided into two main groups as primary and secondary porosity. Primary porosity includes the types of pores formed when the rock first precipitates. Secondary porosity develops due to dissolution, dolomitization, recrystallization and fracture formation during diagenesis. Depending on the depth of burial, the secondary pores are divided into three groups: eugenetic (shallow burial), mesogenetic (deep burial) and telegenetic (regressive burial). In addition, the pores are divided into three groups according to their geometric properties and their relation to the rock fabric. These are fabric selective, not fabric selective, and fabric selective or not. According to their size, the pores are divided into three types: micropore $<4 \mu \mathrm{m}$, mesopore $4 \mu \mathrm{m}-4 \mathrm{~mm}$, and megapore 4-256 $\mathrm{mm}$.

Derleme Makalesi Review Article

Başvuru Tarihi

: 11.10 .2019

Submission Date Accepted Date

Kabul Tarihi

: 18.02 .2020

$: 11.10 .2019$ $: 18.02 .2020$

\section{Giriş}

$\mathrm{Bu}$ makale tortul kayaçlarda gözenek ve gözenek türlerini tanitmakta ve gözeneklerin daha iyi anlaşılmasına katkıda bulunmayı amaçlamaktadır. Gözenekler özellikle karbonat kayaçlarında ortamsal ve diyajenetik değișimleri yorumlamada ve rezervuar analizlerinde kullanılmaktadır. Gözenek (pore) terimi Yunanca sözcük "poros" tan gelmekte ve boşluk veya geçit anlamı taşımaktadır (Choquette ve Pray, 1970; Tucker ve Wright, 1990). Gözeneklilik ise boşluk hacminin $\left(V_{\mathrm{p}}\right)$ kayacın toplam hacmine $\left(\mathrm{V}_{\mathrm{t}}\right)$ oranı olarak tanımlanır (Asquith ve Gibson, 1982). Ø (phi) sembolü ile gösterilir ve aşağıdaki formülle ifade edilir:

$$
\text { gözeneklilik }(\emptyset)=\frac{\text { gözenek hacmi }\left(V_{p}\right)}{\text { kayacın toplam hacmi }\left(V_{t}\right)}
$$

\footnotetext{
*Sorumlu yazar; e-posta : $\underline{\text { m eren@yahoo.com }}$
} 
Porozite değerleri daima birden küçük olduğu için yüzde (\%) değerleriyle ifade edilir. Kayaç içerisindeki boşluk hacmi, gözeneklerde tutulan akışkan (su veya gaz) miktarıyla bulunur. Ayrıca gözeneklilik kayacın, kayacı oluşturan tanelerin ve gözeneklerde bulunan akışkanın yoğunluk ( $\rho$ ) değerlerinden de bulunabilir (Asquith ve Gibson, 1982; North, 1985):

Kuru örneklerde:

$$
\text { gözeneklilik }(\varnothing)=1-\frac{\rho_{\text {kuru kayaç }}}{\rho_{\text {matriks }}}
$$

Gözeneklerde akışkanın bulunması durumunda:

$$
\text { gözeneklilik }(\varnothing)=1-\frac{\rho_{\text {matriks }}-\rho_{\text {kayaç }}}{\rho_{\text {matriks }}-\rho_{\text {akışkan }}}
$$

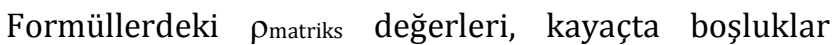
dişında kalan malzemenin yoğunluğunu ifade eder (Pekiner, 2002). Bu değer kumtaşı, kireçtaşı ve dolomit için sırasıyla 2.648, 2.710 ve $2.876 \mathrm{gr} / \mathrm{cm}^{3}$ 'dür. Akışkan

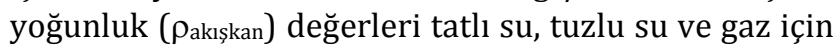
sirasıyla 1.0, 1.1 ve $0.7 \mathrm{gr} / \mathrm{cm}^{3}$ 'dür (Asquith ve Gibson, 1982).

Porozite değerlerinin derinlikle değişimi aşağıdaki formülle ifade edilir (Athy, 1930):

$$
\emptyset_{d}=\emptyset_{y} e^{-c d}
$$

Formülde: $\emptyset_{\mathrm{d}}$ : d gömülme derinliğindeki porozite; $\emptyset_{\mathrm{y}}$ : sedimanın yüzeydeki porozitesi; e (Euler Sayısı) = 2.71828; c (sıkışma katsayısı) $=1.4210^{-3} / \mathrm{m}$; ve $\mathrm{d}$ : derinlik (m).

Gözeneklilik değerleri ve değerlendirmesi Tablo 1' de gösterilmektedir:

Tablo 1.

Gözenekliliğin Nicel Değerlendirilmesi (North, 1985)

\begin{tabular}{ll}
\hline $\begin{array}{c}\text { Gözeneklilik }(\phi) \\
\%\end{array}$ & Nicel Değerlendirme \\
\hline $0-5$ & İhmal edilebilir \\
$5-10$ & Düşük \\
$10-15$ & Orta \\
$15-20$ & İyi \\
$>20$ & Çok iyi \\
\hline
\end{tabular}

\subsection{Etkin Porozite}

Kayaç içerisinde birbiriyle bağlantılı gözeneklerin (Şekil 1) veya sıvıların iletildiği gözenek hacminin $\left(V_{\text {pe }}\right)$ kayacın toplam hacmine $\left(\mathrm{V}_{\mathrm{t}}\right)$ oranıdır (North, 1985; Tiab ve Donaldson, 2004).

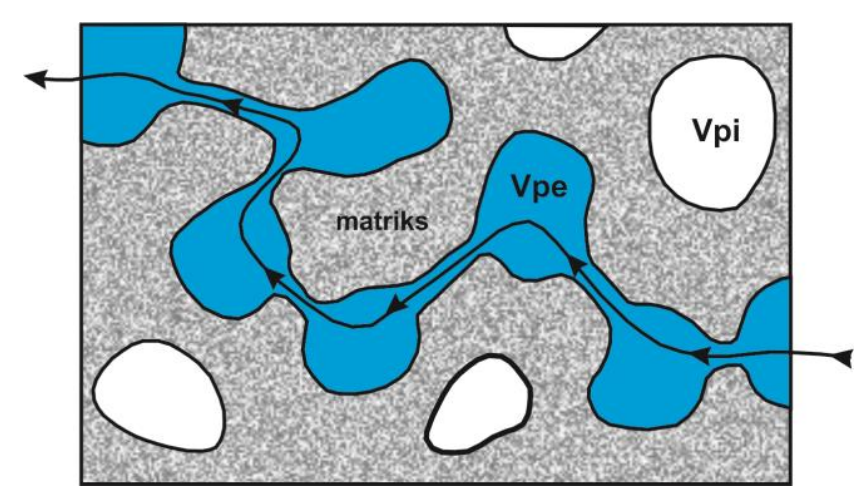

Şekil 1. Sıvıların İletilebildiği Etkin Porozitenin ( $\left.\mathrm{V}_{\mathrm{pe}}\right)$ Şematik Gösterimi. $V_{p i}$ : izole gözenek; matriks: gözenekler arasındaki boşluksuz malzeme (Asquith, 1985'den değiştirilerek).

\section{Kökenlerine Göre Gözenek Sınıflaması}

Kayaçlardaki gözenekler kökensel açıdan birincil ve ikincil olmak üzere başlıca iki gruba ayrılır:

\subsection{Birincil Gözeneklilik (Primary Porosity)}

Kayacın ilk oluştuğu anda, genellikle çökelme sırasında oluşan gözenekliliktir (Choquette ve Pray, 1970; Aguilera,1987; Moore, 1989; Tucker ve Wright, 1990). Kayaç içerisindeki hakim gözenek türlerini ifade eder. Genellikle taneler-arası gözeneklerden oluşur. Ayrıca tane-içi, fenestral (gözlü), korunaklı ve büyüme-çatı tipi gözenekler bu gruba dahil edilir. Birincil gözeneklilik değerleri yeni çökelen kumtaşlarında genellikle \%25-40 ve kireçtaşlarında \%40-70 arasındadır. Bu değerler diyajenez sırasında azalarak kumtaşlarında \%15-30 ve kireçtaşlarında \%5-15' e düşer (Choquette ve Pray, 1970). Birincil porozite değerleri tanelerin boyutuna, boylanmasına, şekline, dizilimine (paketleme biçimine) ve sıkıșmaya bağlı olarak değișir (North, 1985). Kayacı oluşturan tanelerin boyutunda, boylamasında ve küreselliklerindeki artış kayacın gözenekliliğinin artmasına neden olur. Sıkışma ise kayaç içindeki tanelerin daha sıkı paketlenme oluşturacak şekilde yeniden düzenlenmesine ve buna bağlı olarak da boşlukların azalmasına neden olur (Şekil 2; Graton ve Fraser, 1935; North, 1985). Kübik dizilimde tanelerarası boşluk fazladır $(\% 47,64)$. Gevşek çökellerde görülür. $\mathrm{Bu}$ değerler en sıkı paketlenme biçimi olan 
rombohedral dizilimde \%25,95'dir (Serra, 1986; Aguilera, 1987; Görmüş, 2012).

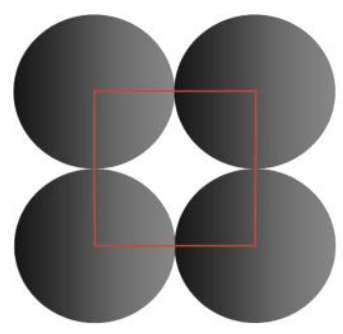

Kübik dizilim $\% 47, .64$

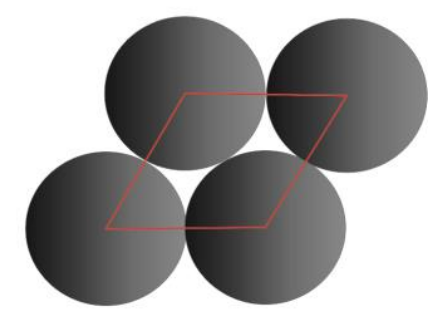

Romboedrik dizilim $\% 25,95$
Şekil 2. Küresel Şekilli Ve Eş Boyutlu Tanelerin Kübik Ve Romboedrik Dizilimlerinde Gözenekliliğin Değişimi.

\section{2. İkincil Gözeneklilik (Secondary Porosity)}

Kayaç içinde çökelmeden sonra yani diyajenez sırasında oluşan gözenekliliktir. İkincil gözeneklilik oluşumunda çözünme, dolomitleşme, yeniden kristallenme ve çatlak oluşumu etkilidir (Choquette ve Pray, 1970; Jardine, Andrews, Wishart ve Young, 1977; Aguilera, 1987). Longman (1982) ve Tucker ve Wright (1990) bunlara stilolit oluşumunu da eklemiștir. İkincil gözenekler oluşum derinliğine bağlı olarak üç gruba ayrılır (Moore, 1989; Tucker ve Wright, 1990):

(i) Öjenetik (eogenetic; erken evre): sı̆̆ gömülme derinliğinde oluşan erken diyajenez (denizel ve tatlı-su) evresini içerir. Tatlı-su diyajenezi yaygındır. Bu evrede oluşan gözenekler genellikle doku seçimlidir.

(ii) Mezojenetik (mesogenetic; geç evre): derin gömülme derinliğinde oluşur ve geç diyajenetik olayları içerir.

(iii) Telejenetik (telegenetic; gerileyici evre): Uyumsuzluklarla birlikte gözlenir. Derin gömülmeye konu olan kayaçların, üzerindeki yükün aşınmasıyla tekrar daha sığ gömülme derinliklerinde tatlı-su diyajenezine uğramasıdır (Moore, 1989).

\section{Temel Gözenek Tipleri}

Karbonat kayaçlarında değişik gözenek sınıflamaları vardır (Choquette ve Pray, 1970; Duran ve Sayll, 1993). Bunlar içinde yaygın olarak kullanılan ve gözenekleri geometrik özelliklerine göre sinıflayan Choquette ve Pray (1970) sinıflamasıdır (Şekil 3). Bu sınıflamada gözenekler doku seçimli ve doku seçimli olmayan gözenekler olmak üzere başlıca iki gruba ayrılır. Ayrıca her iki gruba dahil edilebilen gözenekler de bulunmaktadır.
Doku seçimli gözeneklerde, gözenek şekli kayacın dokusal özelliklerince kontrol edilir (Tucker ve Wright, 1990). Bu grup gözenekler arasında taneler-arası, taneiçi, kristaller-arası, kalıp, fenestral (gözlü), korunaklı, ve büyüme-çatısı gözenekleri bulunur.

Taneler-arası gözeneklilik (intergranular porosity): En yaygın birincil gözenek tipidir. Çökelme sırasında tanelerin arasında oluşur (Şekil 3a). Kırıntılı kayaçlarda yaygındır ve karbonat kayaçlarda da görülür. Çökelme sonrası dönemlerde sıkışma ve çimentolanma gibi diyajenetik olaylarla azalır.

Tane-içi gözeneklilik (intragranular porosity): Tanelerin içinde gözlenen birincil porozite tipidir. Genellikle fosil kavkıları içinde canlıya ait yumuşak kısımların korunduğu bölümlerce oluşturulur (Şekil $3 b)$. Yaygın olarak karbonat kayaçlarında görülür.

Kristaller-arası gözeneklilik (intercrystalline porosity): Kristalli yapıdaki kayaçlarda kristaller arasında görülen gözenek türüdür (Şekil 3c). Bazı yazarlar kayacı olușturan ana gözenek türlerinden olması nedeniyle birincil gözenek grubuna (Tiab ve Donaldson, 2004), bazıları ise diyajenetik olaylardan biri olan dolomitleşmeye bağlı olarak yaygın olarak oluşması nedeniyle ikinci gruba dahil etmektedir (Choquette ve Pray (1970; Tucker ve Wright, 1993).

Kalıp porozite (moldic porosity): Karbonat kayaçlarında tatlı-su ortamında duraysız olan özellikle aragonit ve yüksek magnezyum kalsit bileşimli bileșenlerin (biyoklast, ooid gibi) ve evaporit minerallerinin çözünmesiyle oluşur (Şekil 3d; Atabey, 1997). Gözenek şekli çözünen bileşenin veya mineralin şeklini yansıtır.

Fenestral gözeneklilik (gözlü gözeneklilik; fenestral porosity): Genellikle gel-git düzlüğü ortamında (peritidal environment) laminalanmaya paralel olarak oluşur (Şekil 3e). Uzamış, düzensiz şekillerde görülür. Kurumaya ve çökeller içinde algal dokunun çürümesiyle oluşan gazın kaçışına bağlı olarak oluşur.

Korunaklı gözeneklilik (shelter porosity): Kavkı parçalarının alt kısmında, şemşiye yapısı gibi korunmalı alanlarda oluşan gözenek türüdür (Şekil 3f). Fazla yaygın değildir.

Büyüme-çatı gözenekliliği (growth framework porosity): Resiflerde çatı-yapıcı organizmaların (mercan, stromatolit, kireçli algler gibi) büyümeleri sırasında oluşan gözenekliliktir (Şekil 3g; Moore, 1989).

Doku seçimli olmayan gözenek grubunda gözenekler kayacın dokusunu kesecek şekilde gelişir. Genellikle çözünmeye ve çatlak oluşumuna bağlı olarak gelişir. Bu gruba dahil edilen gözenekler çatlak, kanal, kovuk ve mağaradır. 


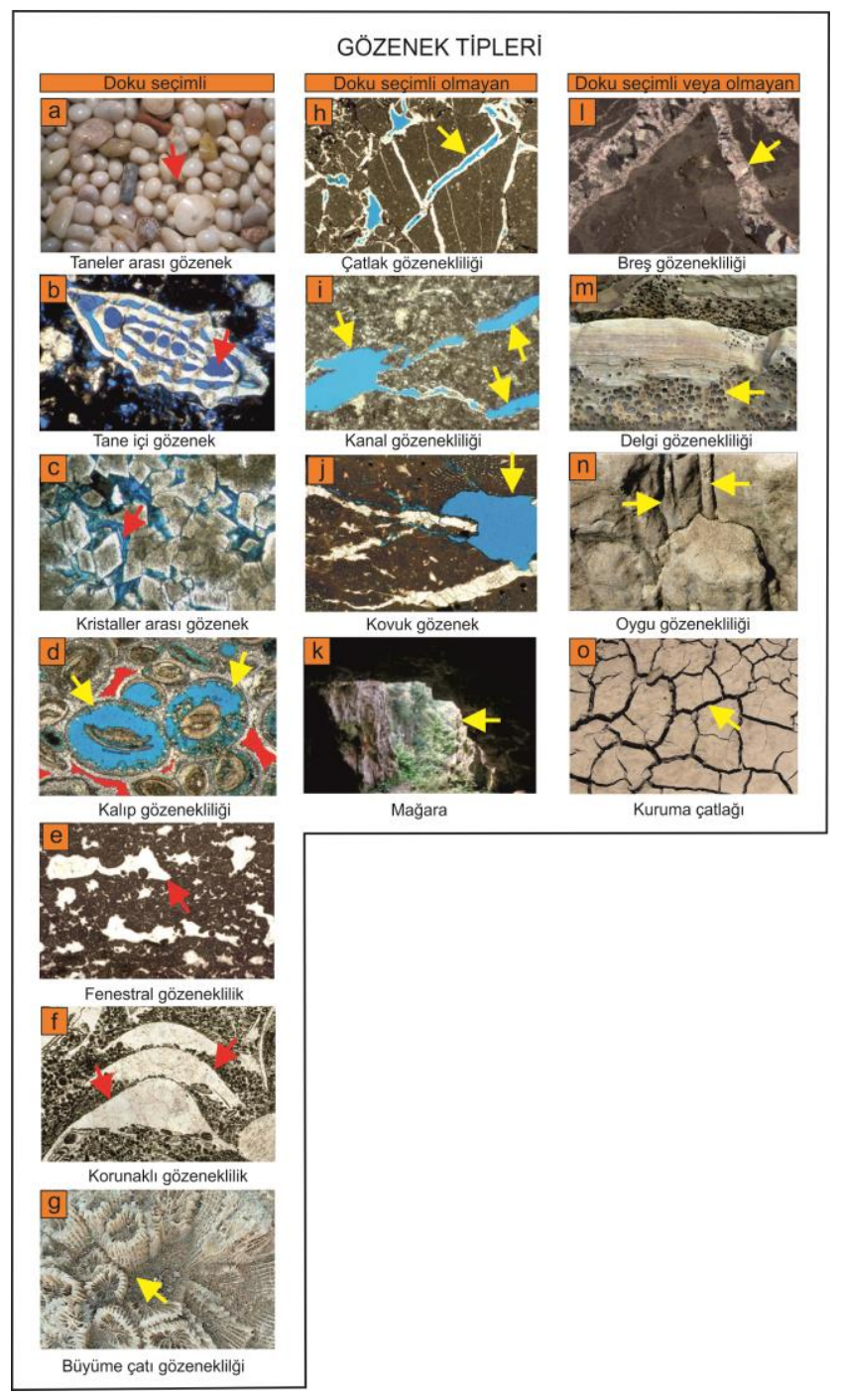

Şekil 3. Temel Gözenek Türleri (Choquette ve Pray, 1970'den değiştirilerek). Fabrik seçimli gözeneklilik: (a) oolitçe zengin plaj çökellerinde taneler-arası gözeneklilik (Eren, Güler, Kadir ve Wanas, 2016); (b) bentik foraminifer (nummulit) localarından oluşan tane-içi gözeneklilik (c) dolomit kristalleri arasındaki kristaller-arası gözeneklilik, (d) oolitin çözünmesiyle oluşmuş kalıp porozitesi (oomoldic; mavi renk); (e) mikrit içinde uzamış, düzensiz şekilli ve sparit dolgu içeren fenestral (gözlü) gözeneklilik; (f) ters dönmüş pelecypod kavkısı altında kalmış, kalsit dolgulu korunmalı gözeneklilik; ( $\mathrm{g}$ ) resif yapıcı organizmaların (mercan) büyümeleri sırasında ve içinde oluşan büyüme-çatı gözenekliliği (Casazza, 2017). Fabrik seçimli olmayan gözeneklilik: (h) mikritik kireçtașı içindeki çatlak gözenekliliği (Meneses, Mendes, Abreu ve Rocha, 2013); (i) mikritik kireçtaşında çatlakların çözünmeyle genişletilmesi sonucu oluşan kanal gözenekliliği; (j) Orbitolinid'li kireçtaşında çözünmeyle oluşmuş, sınırları fosil ve çatlakları kesen kovuk (vuggy) gözenekliliği; (k) kireçtaşı içinde çözünmeyle oluşan mağara. Fabrik seçimli veya olmayan: (l) mikritik kireçtaşında çatlak oluşumuna bağlı olarak gelișen tektonik breș ve bileșenler arasındaki kalsit dolgulu breș gözenekliliği; (m) kayaç içinde gözlenen pelecypod delgi yapıları (gözenekliliği) (King, 2003); (n) organizmalar tarafından oluşturulan oygu yapısı (gözenekliliği) iç dolgusu (iz fosil; trace or ichno fossil; Winder, 2011); (o) poligonal şekilli kuruma çatlaklarına bağlı olarak gelișen gözeneklilik. [(b-f) ve (h-j) Scholle ve Ulmer-Scholle, 2003'den]. Oklar ilgili gözenekleri göstermektedir.
Çatlak gözenekliliği (fracture porosity): Genellikle geç diyajenetik evrede gömülme ve sıkışmaya bağlı olarak oluşur. Çatlak veya faylanma ile ilişkili gözenekliliktir (Şekil 3h).

Kanal gözenekliliği (channel porosity): Çözünmeyle çatlaklar ve stilolitler boyunca gelișen uzamıș ve düzensiz șekilli gözeneklere denir (Șekil 3i). Kayacın dokusal özelliklerini gelişigüzel kesebilir. Kanal porozitesinin uzunluğu, kanal genişliğinin 10 katı veya daha fazlasıdır. Eğer kanal genişliği 1/16 mm'den daha az ise buna mikrokanal adı verilir.

Kovuk porozitesi (vuggy porosity): Çözünmeyle oluşmuş, doku seçimli olmayan, çıplak gözle ayırt edilebilen (çapı > 1/16 mm), yaklaşık eş boyutlu, düzensiz şekilli boşluklara denir (Şekil 3j).

Mağara (cavern): Çözünmeyle oluşmuş, yetişkin bir insanın rahatlıkla sığabileceği boşluklara denir.

Üçüncü gruba dahil gözenekler fabrik seçimli olabilir veya olmayabilir. Bu gruba breş, delgi, oygu poroziteleri ve kuruma çatlakları dahildir.

Breş porozitesi (breccia porosity): Breşlerde gözlenen bir çeşit taneler-arası gözenekliliktir. Köșeli tanelerin çökelmesi veya çökelme sonrası kayaçta çökmeye ve çatlak oluşumuna bağlı olarak oluşabilir. Diyajenez sırasında kayacın breşik yapı kazanmasına breşleşme, oluşan breşe oluşum mekanizmasina göre çatlak breşi (Şekil 3l), fay breşi, tektonik breş ve çökme breşi adları verilir (Tucker ve Wright, 1990).

Delgi gözenekliliği (boring porosity): Delici organizmalar (clinoid süngerler, pelecypod gibi) tarafından sertleşmiş zeminlerde açlan boşluklara denir (Şekil m). Boşluk duvarları zeminin sertliğinden dolayı düzenlidir.

Oygu gözenekliliği (burrow porosity): Oyucu organizmalar tarafindan göreceli olarak gevşek zeminlerde açllan boşluklara denir (Şekil 3n). Zeminin gevşek olmasından dolayı gözenek duvarında yıkılmalardan dolayı düzensizlikler görülür.

Büzülme veya kuruma porozitesi(shrinkage porosity): Kurumayla bağlı olarak oluşan çatlak porozitesidir (Şekil 3o). Çamurtaşlarında ve mikritik kireçtaşlarında yaygindır.

\section{Boyutlarına Göre Gözenek Sınıflaması}

Gözenekler boyutlarına göre de üç gruba ayrılır: (i) mikrogözenek (micropore) $<4 \mu \mathrm{m}$; (ii) orta gözenek (mesopore) $4 \mu \mathrm{m}-4 \mathrm{~mm}$; büyük gözenek (megapore) 4256 mm (Choquette ve Pray, 1970). 


\section{Sonuçlar}

Gözenekler tortul kayaçların en önemli özelliklerinden birisidir ve kökensel olarak birincil ve ikincil olmak üzere başlıca iki gruba ayrılır. Birincil gözenekler genellikle çökelme sırasında oluşur. İkincil gözeneklilik ise çökelmeden sonra diyajenez sırasında çözünme, dolomitleşme, yeniden kristallenme ve çatlak oluşumuna bağlı olarak gelişir. İkincil gözenekler gömülme derinliğine bağlı olarak da üçe gruba ayrılır: öjenetik (sığ gömülme), mezojenetik (derin gömülme) ve telejenetik (gerileyici gömülme). Ayrıca gözenekler kayacın dokusuyla olan ilişkisine göre: (i) fabrik seçimli, (ii) fabrik seçimli olmayan, ve (iii) fabrik seçimli veya olmayan olarak üçe ayrılır. Gözenekler boyutlarına göre de mikro, orta ve büyük olmak üzere üç grupta toplanır.

\section{Etik Beyanı}

Bu çalışmada araştırma ve yayın etiğine uyulmuştur.

\section{Kaynaklar}

Aguilera, R. (1987). Geologic aspects. In: Beaumont, E.A. and Foster, N.H. (eds). Reservoirs I Properties. AAPG Treatise Petroleum Geology Reprint Series, No. 3, 260305.

Asquith, G.B. (1985). Handbook of log evaluation techniques for carbonate reservoirs. AAPG Methods in Exploration Series No. 5, 47.

Asquith, G.B. \& Gibson, C.R, (1982). Basic well log analysis for geologists. AAPG Methods in Exploration Series No. 3, 216.

Atabey, E. (1997). Karbonat sedimantolojisi. TMМOB Jeoloji Mühendisleri Odası Yayınları 45.

Athy, L.F. (1930). Density, porosity and compaction of sedimentary rocks. Bulletin of the American Association of Petroleum Geologists, 14, 1-24. Doi : https://doi.org/10.1306/3D93289E-16B1-11D78645000102C1865D

Casazza, L.R. (2017). Pleistocene reefs of the Egyptian Red Sea: environmental change and community persistence. PeerJ, 5:e3504. doi: https://doi.org/ $10.7717 /$ peerj. 3504

Choquette, P.W. \& Pray, L.C. (1970). Geologic nomenclature and classification of porosity in sedimentary carbonates. American Association of Petroleum Geologists Bulletin, 54, 207-250. Doi : https://doi.org/10.1306/5D25C98B-16C1-11D78645000102C1865D

Duran, O. ve Sayıl, A. (1993). Karbonat diyajenezi ve porozite. Duran, O. ve Şengündüz, N. (ed.), Karbonat kayaları ve rezervuar özellikleri. Ankara: TPAO Araştırma Merkezi Grubu Başkanlığı Eğitim Yayınları No: 24, 75-97.
Eren, M., Güler, C., Kadir, S. \& Wanas, H. (2016). Sedimentological, mineralogical and geochemical characteristics of the ooids in Cleopatra (Sedir Island, Gökova Bay, SW Turkey) and Alexandria (NW Egypt) Beach sediments: A comparison and reality of myth of the love. Chemie der Erde, 76, 157-169.

Görmüş, M. (2012). Sedimantoloji ve stratigrafi ilkeleri. Ankara: Ankara Üniversitesi Yayını.

Graton, L.C. \& Fraser, H.J. (1935). Systematic packing of spheres- with particular relation to porosity and permeability. Journal of Geology, 43, 785-909. Doi : https://doi.org/10.1086/624386

Jardine, D., Andrews, D.P., Wishart, J.W. \& Young, J.W. (1977). Distribution and continuity of carbonate reservoirs. Journal of Petroleum Technology 29, 873885. Doi: https://doi.org/10.2118/6139-PA

King, N.R. (2003). Bivalve borings. Erişim adresi: http://www.lakeneosho.org/Paleolist/69/Lrg1.html

Longman, M.W. (1982). Carbonate diagenesis as a control on stratigraphic traps. AAPG Education Course Note Series 21, 159 p.

Meneses, R.M.X., Mendes, J.S., Abreu, C.J. \& Rocha, P.L.F. (2013). Petrophysic and Petrologic Characterization of Carbonate Rocks of the São José do Itaboraí Basin, RJ. 13th International Congress of the Brazilian Geophysical Society, Rio de Janeiro, Brazil, 1-4.

Moore, C.H. (1989). Carbonate diagenesis and porosity. Developments in Sedimentology 46, Amsterdam: Elsevier.

North, F.K. (1985). Petroleum geology. London, UK: Chapman and Hall.

Pekiner, Y. (2002). Kuyu Logları Tekniğiyle Yeraltının Keşfi. Ankara: Seçkin Yayıncılık.

Scholle, P.A. \& Ulmer-Scholle, D.S. (2003). A color guide to the petrography of carbonate rocks- grains, textures, porosity, diagenesis. AAPG Memoir 77, 459 p.

Serra, 0. (1986). Fundamentals of well-log interpretation-2.the interpretation of logging data. Developments in Petroleum Science 15B, Amsterdam: Elsevier.

Tiab, D. \& Donaldson, E.C. (2004). Petrophysics - Theory and practice of measuring reservoir rock and fluid transport properties. New York: Gulf Professional Publishing.

Tucker, M.E. \& Wright, V.P. (1990). Carbonate sedimentology. Oxford: Blackwell.

Winder, J. (2011). Fossil worm burrows and scallops at Bran Point. Erișim adresi: https://natureinfocus. blog/2011/07/09/fossil-worm-burrows-scallopsat-bran-point/ 